\title{
Analysis on the Influence of Teachers' Evaluation on Students' Learning Effect in Application-Oriented Universities
}

\author{
Rong Chen \\ Department of Physics, Nanchang Normal University, Nanchang, China \\ Email:xinseafank@163.com
}

How to cite this paper: Chen, R. (2020) Analysis on the Influence of Teachers' Evaluation on Students' Learning Effect in Application-Oriented Universities. Open Access Library Journal, 7: e6865.

https://doi.org/10.4236/oalib.1106865

Received: September 26, 2020

Accepted: October 26, 2020

Published: October 29, 2020

Copyright $\odot 2020$ by author(s) and Open Access Library Inc.

This work is licensed under the Creative Commons Attribution International License (CC BY 4.0).

http://creativecommons.org/licenses/by/4.0/

\begin{abstract}
This paper finds out the existing problems in learning and implements effective intervention to stimulate students' enthusiasm for learning by analyzing the teachers' evaluation data of all classes in a semester. The results show that there is a significant positive correlation at the level of 0.01 through the correlation analysis of learning attitude, learning process and learning effect, and the correlation is above medium level. The prediction model of learning effect is established through regression analysis, which improves students' awareness of autonomous learning, standardizes the learning process and improves the learning effect.
\end{abstract}

\section{Subject Areas}

Education

\section{Keywords}

Teachers' Evaluation, Learning Attitude, Learning Process, Learning Effect, Regression Analysis

\section{Introduction}

Teachers' evaluation system is an important part of teaching quality monitoring, which is an important segment in teaching quality management. Teachers' evaluation is the overall evaluation of the students' learning status in the class, which is to effectively collect relevant information on the front line of teaching, which is an effective information channel to reflect the learning atmosphere of the class. It is helpful to improve teachers' teaching level, helps students find their 
own problems in learning, improves students' learning quality and learning effect, and promotes emotional communication between teachers and students through teachers' evaluation. Find out the important factors that affect the teaching quality through the regression analysis of SPSS software, so as to improve the quality of classroom teaching and learning effect.

Teachers' evaluation can find out the shortcomings and problems existing in the learning process of students, and implement targeted teaching intervention through the analysis of the influencing factors. The university implements the teaching intervention, which stimulates the student's intrinsic study motivation and the study enthusiasm, which develops the habit of self-directed learning. The problems and deficiencies in teaching management are reflected in the students' learning status and learning effect. The school adopts rectification measures to push forward teaching reform and management reform.

\section{Research Questions}

1) Whether there is correlation among learning attitude, learning process and learning effect.

2) Whether the evaluation indexes such as learning attitude, learning process and learning effect can be regressed and the prediction model of learning effect can be established.

\section{Research Objects}

Take eight undergraduate classes of Physics Department of Nanchang Normal University as the research object. The teachers mainly evaluate the students' learning from three aspects: learning attitude, learning process and learning effect. The learning state of each class is graded by the teacher.

\section{Research Results}

The results of teachers' evaluation are divided into four grades based on students' actual performance and teachers' experience in evaluating learning: excellent (above 90), good (76 - 89), average (60 - 75) and poor (below 59). There are 10 indicators of teachers' evaluation, each of which has a score of 10 , a total of 100.

\section{1) The situation of teachers' evaluation in each class}

In the evaluation of physics teachers, the scores of eight classes are as follows: class one 76.41 , class two 87.75 , class three 80.33 , class four 80.33 , class five 86.82 , class six 80.47 , class seven 80.78 and class eight 85.56 . As shown in Table 1 , the scores of each class are greater than 76 , less than 89 , so all classes get a "good" grade.

\section{2) Independent analysis of teachers' evaluation in each class}

a) Learning attitude

From the results of teachers' evaluation of learning, as shown in Table 2, the average score of class two's learning attitude is 9.25 , with good learning attitude. 
Table 1. The teachers' evaluation in each class.

\begin{tabular}{cccc}
\hline class & mean & $\mathrm{N}$ & standard deviation \\
\hline class one & 76.4063 & 16 & 8.51316 \\
class two & 87.7500 & 20 & 9.83081 \\
class three & 80.3333 & 15 & 12.42358 \\
class four & 80.3333 & 15 & 12.35150 \\
class five & 86.8182 & 11 & 10.00568 \\
class six & 80.4688 & 16 & 8.02178 \\
class seven & 80.7813 & 16 & 8.50092 \\
class eight & 85.5556 & 9 & 9.74501 \\
total & 82.1398 & 118 & 10.42000 \\
\hline
\end{tabular}

Table 2. The learning attitude of teachers' evaluation in each class.

\begin{tabular}{cccc}
\hline class & mean & $\mathrm{N}$ & standard deviation \\
\hline class one & 8.5938 & 16 & 0.77392 \\
class two & 9.2500 & 20 & 1.10322 \\
class three & 8.7500 & 15 & 1.49404 \\
class four & 8.4167 & 15 & 1.45365 \\
class five & 8.9773 & 11 & 1.09233 \\
class six & 8.2813 & 16 & 1.10633 \\
class seven & 8.2031 & 16 & 1.11512 \\
class eight & 9.0278 & 9 & 1.21478 \\
total & 8.6758 & 118 & 1.20421 \\
\hline
\end{tabular}

The average score of other evaluated classes is greater than 8.20, and all of them have correct learning attitude. In the early stage of this semester, due to the impact of the epidemic, most of the courses are online teaching. Under such circumstances, students in each class can abide by the teaching management system, have a high attendance rate, do not arrive late and leave early. Also the classroom order is good, which reflects the good study style of the class.

\section{b) Learning process}

According to the evaluation index of learning process, the average score of class five is 8.77 , which is the highest score of each class. The average score of class one is 7.25, which is the lowest score of each class, as shown in Table 3. For online teaching courses, students are required to prepare before class and review after class. Some courses also need to read a lot of professional literature, so as to grasp the learning content. But teachers reflect that some students' self-learning ability is weak, and some students lack the consciousness of active learning. The interaction is not active enough between students and teachers in most classes, and some students lack of their own thinking about the problem.

\section{c) Learning effect}

As can be seen from Table 4, the learning effect of class two is the best, class 
Table 3. Learning process of teachers' evaluation in each class.

\begin{tabular}{cccc}
\hline class & mean & $\mathrm{N}$ & standard deviation \\
\hline class one & 7.2500 & 16 & 1.06458 \\
class two & 8.6750 & 20 & 0.94972 \\
class three & 7.8000 & 15 & 1.34695 \\
class four & 7.9333 & 15 & 1.61319 \\
class five & 8.7727 & 11 & 1.21169 \\
class six & 8.0938 & 16 & 1.08349 \\
class seven & 8.0625 & 16 & 1.01448 \\
class eight & 8.5556 & 9 & 1.10240 \\
total & 8.1144 & 118 & 1.24106 \\
\hline
\end{tabular}

Table 4. The learning effect of teachers' evaluation in different classes.

\begin{tabular}{cccc}
\hline class & mean & $\mathrm{N}$ & standard deviation \\
\hline class one & 7.6563 & 16 & 1.14741 \\
class two & 8.6250 & 20 & 1.18701 \\
class three & 7.9444 & 15 & 1.36810 \\
class four & 7.9444 & 15 & 1.08501 \\
class five & 8.3333 & 11 & 1.23603 \\
class six & 7.8125 & 16 & 0.67185 \\
class seven & 8.0208 & 16 & 0.95622 \\
class eight & 8.2407 & 9 & 0.97222 \\
total & 8.0720 & 118 & 1.10950 \\
\hline
\end{tabular}

five is the second, and class one is the last. In terms of learning effect, the score of "learning flexibly, being able to use learned knowledge to put forward, analyze and solve practical problems" is generally low. Teachers think that some students' practical ability is a little poor, and the ability of autonomous learning and practical innovation needs to be further improved.

In a word, teachers generally agree with the style of study of the evaluated class, but think that the students' self-learning ability, the ability of integrating theory with practice, and the ability of "learning flexibly" need to be further improved.

\section{The Correlation Analysis among Learning Attitude, Learning Process and Learning Effect}

It can be seen from Table 5 that there is a significant correlation between learning attitude and learning process at the level of 0.01 , and the correlation coefficient is 0.538 , so the correlation between learning attitude and learning process is positive, and the correlation is moderate. There is a significant correlation between learning attitude and learning effect at the level of 0.01 , and the correlation coefficient is 0.505 , that is, the correlation between learning attitude and 
Table 5. Correlation among learning attitude, learning process and learning effect.

\begin{tabular}{ccccc}
\hline & & $\begin{array}{c}\text { learning } \\
\text { attitude }\end{array}$ & $\begin{array}{c}\text { learning } \\
\text { process }\end{array}$ & $\begin{array}{c}\text { learning } \\
\text { effect }\end{array}$ \\
\hline \multirow{2}{*}{ learning attitude } & Pearson correlation & 1 & $0.538^{* *}$ & $0.505^{* *}$ \\
& Significance (bilateral) & & 0.000 & 0.000 \\
& N & 118 & 118 & 118 \\
learning process & Pearson correlation & $0.538^{* *}$ & 1 & $0.702^{* *}$ \\
& Significance (bilateral) & 0.000 & & 0.000 \\
& N & 118 & 118 & 118 \\
learning effect & Pearson correlation & $0.505^{* *}$ & $0.702^{* *}$ & 1 \\
& Significance (bilateral) & 0.000 & 0.000 & 118 \\
\hline
\end{tabular}

${ }^{*}$ There is a significant correlation at 0.01 level (bilateral).

learning effect is positive, and the correlation coefficient is 0.505 . There is a significant correlation between learning process and learning effect at the level of 0.01 , and the correlation coefficient is 0.702 , which means that the correlation between learning process and learning effect is positive, and the correlation is strong.

\section{Regression Analysis among Learning Process, Learning Attitude and Learning Effect}

Taking model 4 as an example, the model uses input method, learning process and learning attitude as independent variables, learning effect as dependent variables, Table 6 is the summary of model 4 . From Table 6 , we can see that $R$ is the complex correlation coefficient, $\mathrm{R}=0.718, \mathrm{R}^{2}$ is the determination coefficient, which is used to reflect the interpretation degree of the established model, $\mathrm{R}^{2}=0.516$. Learning process and learning attitude are used to predict learning effect, and the prediction accuracy is $51.6 \%$. The value of Durbin Watson in model 1 is 1.961 , ranging from 1.8 to 2.2 , which meets the independent condition of linear regression. The value of Durbin Watson in model 4 is 1.901, ranging from 1.8 to 2.2, which meets the condition of independence of linear regression. The value of DurbinWatson in model 2 and model 3 is not ranging from 1.8 to 2.2 , which does not meet the condition of independence of linear regression. Table 7 is the statistical test results of model 4 , and ANOVA is used to test whether the model has statistical significance. The test result is $\mathrm{F}=61.234, \mathrm{P}=$ $0.000<0.05$, that is, the regression model of learning effect constructed by learning process and learning attitude is statistically significant [1] [2] [3].

Table 8 shows the coefficients of the constructed model 4 , and it can be concluded that the prediction model 4 is:

$$
Y=2.247+0.165 \times K_{1}+0.541 \times K_{2}
$$

Among them, $K_{1}$ is learning attitude, $K_{2}$ is learning process, and $Y$ is predicted learning effect. 
Table 6. The learning effect of teachers' evaluation in different classes.

\begin{tabular}{cccccc}
\hline model & $\mathrm{R}$ & $\mathrm{R}^{2}$ & Adjust $^{2}$ & $\begin{array}{c}\text { Error of standard } \\
\text { estimation }\end{array}$ & Durbin-Watson \\
\hline 1 & $0.702^{\mathrm{a}}$ & 0.493 & 0.489 & 0.79345 & 1.961 \\
2 & $0.538^{\mathrm{a}}$ & 0.290 & 0.284 & 1.01921 & 1.337 \\
3 & $0.505^{\mathrm{a}}$ & 0.255 & 0.249 & 0.96166 & 1.487 \\
4 & $0.718^{\mathrm{a}}$ & 0.516 & 0.507 & 0.77879 & 1.901 \\
\hline
\end{tabular}

Table 7. ANOVAa

\begin{tabular}{ccccccc}
\hline & model & square sum & df & $\begin{array}{c}\text { mean } \\
\text { square }\end{array}$ & F & Sig. \\
\hline \multirow{4}{*}{1} & regression & 70.997 & 1 & 70.997 & 112.772 & $0.000^{\mathrm{b}}$ \\
& residual & 73.029 & 116 & 0.630 & & \\
& total & 144.027 & 117 & & & \\
& regression & 49.165 & 1 & 49.165 & 47.329 & $0.000^{\mathrm{b}}$ \\
& residual & 120.499 & 116 & 1.039 & & \\
& total & 169.664 & 117 & & & \\
& regression & 36.751 & 1 & 36.751 & 39.739 & $0.000^{\mathrm{b}}$ \\
& residual & 107.276 & 116 & 0.925 & & \\
& total & 144.027 & 117 & & & \\
& regression & 74.278 & 2 & 37.139 & 61.234 & $0.000^{\mathrm{b}}$ \\
& residual & 69.749 & 115 & 0.607 & & \\
\hline
\end{tabular}

Table 8. Coefficients ${ }^{\mathrm{a}}$.

\begin{tabular}{|c|c|c|c|c|c|c|}
\hline & \multirow{2}{*}{ model } & \multicolumn{2}{|c|}{$\begin{array}{c}\text { Coefficient of } \\
\text { non standardization }\end{array}$} & \multirow{2}{*}{ 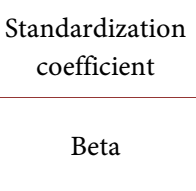 } & \multirow{2}{*}{$\mathrm{t}$} & \multirow{2}{*}{ Sig. } \\
\hline & & B & $\begin{array}{l}\text { Standard } \\
\text { error }\end{array}$ & & & \\
\hline \multirow{2}{*}{1} & (constant) & 2.979 & 0.485 & & 6.140 & 0.000 \\
\hline & learning process & 0.628 & 0.059 & 0.702 & 10.619 & 0.000 \\
\hline \multirow{2}{*}{2} & (constant) & 4.437 & 0.623 & & 7.121 & 0.000 \\
\hline & learning process & 0.522 & 0.076 & 0.538 & 6.880 & 0.000 \\
\hline \multirow{2}{*}{3} & (constant) & 4.034 & 0.647 & & 6.239 & 0.000 \\
\hline & learning attitude & 0.465 & 0.074 & 0.505 & 6.304 & 0.000 \\
\hline \multirow{3}{*}{4} & (constant) & 2.247 & 0.571 & & 3.936 & 0.000 \\
\hline & learning attitude & 0.165 & 0.071 & 0.179 & 2.326 & 0.022 \\
\hline & learning process & 0.541 & 0.069 & 0.606 & 7.866 & 0.000 \\
\hline
\end{tabular}

Model 1: a. dependent variable: learning effect b. predictive variable: (constant), learning process. Model 2: a. dependent variable: learning attitude b. predictive variable: (constant), learning process. Model 3: a. dependent variable: learning effect b. predictive variable: (constant), learning attitude. Model 4: a. dependent variable: learning effect $b$. predictive variable: (constant), learning process, learning attitude. 


\section{Improvement Measures}

Adhering to the principle of promoting improvement through evaluation, the department will take the following measures according to the results of the teachers' evaluation:

1) None of the classes got "excellent" in the evaluation results, so we should further improve the style of study and class atmosphere, for example, it is necessary to establish one-to-one help group for learning difficulties, and advocate evening self-study and tutorial system. The results will be fed back to all classes, counselors and class teachers will organize theme class meetings to further strengthen the education of class atmosphere and class atmosphere.

2) In the teaching process, teachers should pay attention to the students' learning state, whether the students can keep up with the teachers' thinking in class, and make the students and teachers' explanation ideas reach the same frequency resonance. Experimental courses should not only focus on cultivating students' practical ability, but also cultivate students' ability to analyze and solve problems. The tutor should guide the students to think independently.

\section{Conclusions}

There is a significant positive correlation at the level of 0.01 through the correlation analysis of learning attitude, learning process and learning effect, and the correlation is above medium level. The prediction model of learning effect is established through regression analysis, which improves students' awareness of autonomous learning, standardizes the learning process and improves the learning effect.

The data of teachers' evaluation is too small, and only one semester sample is selected, so it is difficult to observe the results of teachers' evaluation comprehensively. In the future, the selected time period should be longer and the sample size should be larger to eliminate the interference of accidental factors.

\section{Acknowledgements}

The project was funded by Jiangxi Provincial Department of Education (Grant No. GJJ191124). Project supported by Training program for college students in Jiangxi Province (Grant No. S202014437004, S202014437012) and also by the research on teaching reform of Nanchang Normal University (Grant No. JGKT-19-12). The main contribution of this paper is to construct the prediction model of the projects, which provides the basis for the in-depth discussion of the projects.

\section{Conflicts of Interest}

The author declares no conflicts of interest regarding the publication of this paper.

\section{References}

[1] Chen, R. (2020) Study on the Influencing Factors of Teaching Effect of University 
Teachers during the Period of the Epidemic. Open Access Library Journal, 7, e6604. https://doi.org/10.4236/oalib.1106604

[2] Chen, R. (2020) Analysis and Prediction of the Final Grade of Securities and Futures Based on SPSS. International Journal of Trend in Scientific Research and Development, 4, 394-396.

[3] Zheng, J. and Lv, S. (2020) Regression Analysis Based on Social Media Promotion. World Scientific Research Journal, 6, 58-63. 